\title{
A Versatile Surface Modification Method via Vapor-phase Deposited Functional Polymer Films for Biomedical Device Applications
}

\author{
Younghak Cho, Minseok Lee, Seonghyeon Park, Yesol Kim, Eunjung Lee, and Sung Gap Im
}

Received: 21 August 2020 / Revised: 5 October 2020 / Accepted: 8 October 2020

(C) The Korean Society for Biotechnology and Bioengineering and Springer 2021

\begin{abstract}
For last two decades, the demand for precisely engineered three-dimensional structures has increased continuously for the developments of biomaterials. With the recent advances in micro- and nano-fabrication techniques, various devices with complex surface geometries have been devised and produced in the pharmaceutical and medical fields for various biomedical applications including drug delivery and biosensors. These advanced biomaterials have been designed to mimic the natural environments of tissues more closely and to enhance the performance for their corresponding biomedical applications. One of the important aspects in the rational design of biomaterials is how to configure the surface of the biomedical devices for better control of the chemical and physical properties of the bioactive surfaces without compromising their bulk characteristics. In this viewpoint, it of critical importance to secure a versatile method to modify the surface of various biomedical devices. Recently, a vapor phase method, termed initiated chemical vapor deposition (iCVD) has emerged as damage-free method highly beneficial for the conformal deposition of various functional polymer films onto many kinds of micro- and nano-structured surfaces without restrictions on the substrate material or geometry, which is not trivial to achieve by conventional solutionbased surface functionalization methods. With proper structural design, the functional polymer thin film via
\end{abstract}

Younghak Cho ${ }^{\dagger}$, Minseok Lee`, Seonghyeon Park, Yesol Kim, Eunjung Lee*, Sung Gap Im*

Department of Chemical and Biomolecular Engineering, Korea Advanced of Institute of Science and Technology, Daejeon 34141, Korea

Tel: +82-42-350-3976; Fax: +82-42-350-3910

E-mail: ejung0608@kaist.ac.kr

Tel: +82-42-350-3936; Fax: +82-42-350-3910

E-mail:sgim@kaist.ac.kr

These authors contributed equally.
iCVD can impart required functionality to the biomaterial surfaces while maintaining the fine structure thereon. We believe the iCVD technique can be not only a valuable approach towards fundamental cell-material studies, but also of great importance as a platform technology to extend to other prospective biomaterial designs and material interface modifications for biomedical applications.

Keywords: initiated chemical vapor deposition (iCVD), surface modification, non-flat surfaces, biomedical applications

\section{Introduction}

Great progress has been made in the field of biomedical applications with advance in novel biomaterials [1-4]. However, most conventional materials such as metals, polymers, hydrogels, carbons, and composites do not always meet the demands required for biomaterials in both their surface and bulk properties. Therefore, a myriad of surface modification methods have been applied to the materials for providing a proper chemical and physical properties such as biocompatibilities, surface functionalities, and mechanical strength in the field of tissue engineering, regenerative medicine, and biomedical devices [5-9]. Since the surface characteristics such as topographic and geometric features can regulate the cellular response, researchers in this area continuously attempted to create scaffolds with specific surface functionalities via surface modification, which can offer several advantages compared to flat surface including cell adhesion and cell fate decision [10-14]. The surface of medical devices also has been modified to provide additional functionalities such as sensing, diagnosis, or treatment [15-18].

For the recapitulation of cellular microenvironments, a 
large number of biomaterial scaffolds have been developed extensively by imparting biological character to synthetic materials [19-23]. Such artificial scaffolds targeted for a substitute for tissue grafts have been used for the restoration and reconstruction of damaged tissue such as vessels, nerves, muscles, and bones [24-27]. They provide a mechanical support while promoting various functions such as cell attachment, proliferation, extracellular matrix (ECM) generation, and restoration. For such purposes, mechanical (stiffness, elastic modulus, etc.), physicochemical (surface chemistry, porosity, biodegradation, etc.), and biological (cell adhesion, biocompatibility, etc.) requirements should be met for the design of the scaffold. Simultaneously, the scaffold should also be designed and fabricated in a manner to resemble the anatomical structure and mimicking the function and biomechanics of the original tissue. Therefore the scaffold with its topography and mechanical features that can mimic the nanoscale topographical features of cells become a promising application for the reconstruction of tissue repair and regeneration [28-30].

The bulk property of a material is an important factor to reflect a biological environment and often a key factor in material selection for a particular application. The subcellular interactions at the cell-substrate material interface also significantly influence the cell behaviors and their key features at the molecular and cellular levels [31-34]. Recently, many studies have been reported how cells sense and respond the mechanophysical signals given by the cell culture or scaffold substrates, especially for stem cells $[10,35]$. In this point of view, the modulation of cell interactions with the scaffold surface become a key consideration for generating bioactive scaffold. Indeed many efforts have been focused on the surface modification methods to reduce initial barriers of synthetic scaffolds to cell adhesion, proliferation, and differentiation such as topographical modification, cellular components (growth factors, hormones, ECM proteins, etc.) and mineral deposition.

Topographical modifications with micron and nanometer ranges regulate the cell adhesion and elicit more specific cell responses, such as directing mobility and governing differentiation pathways [12,36,37]. Chemical etching has been employed to increase the surface roughness and hydrophilicity of the scaffold. The modified poly(lactic-coglycolic acid) (PLGA) scaffold by the chemical etching resulted in $500 \%$ increase in nanoscale surface roughness and enhanced vascular cell attachment and chondrocyte development [38]. To generate biomimetic surface, bioactive molecules such as short peptide sequences in ECM proteins and growth factors have also been incorporated into the scaffold surface by using a covalent [39-42], chemisorptive $[43,44]$, and physisorptive techniques $[45,46]$. One of the most popular and well-studied ECM fragments is the arginine-glycine-aspartic acid (RGD) motif found in most ECM proteins (such as fibronectin, laminin, and vitronectin) [47-49], which have been coupled to various biomaterials such as hyaluronic acid and poly(ethylene glycol)-based hydrogels, titanium implants, polyurethane, and poly (dimethly siloxane) (PDMS) surfaces [50-53].

So far, considerable progress has been made in biomaterials with micro- or nano-architectures. Recently, with a significant advancement in microfabrication method, micro- and nanodevices become another interesting biomedical application [54,55]. They can provide a number of advantages and possibilities for the study of biological, chemical and physical processes at the cellular scale. However, the surface modification method to modulate interactions between cells and biomaterials still limit their medical and biological applications. The major difficulties lie in the limitation of the bulk surface modification method based on wet-chemical approaches in several aspects. First of all, the surface modification of structurally complexed scaffolds such as porous membrane and nano-/ micro-fabricated materials is challenging using wet-chemical method because the chemical solutions may cover or clog the designed microstructures, resulting in the distortion of the initial microstructures. Moreover a prolonged exposure of chemical solution often ruin the integrity of the delicate structures.

In this regard, it is critically important to develop a versatile method capable of surface modification without damaging the bulk of the biomaterials. Recently, a new vapor-phase deposition method, called initiated chemical vapor deposition (iCVD) was emerged as a powerful tool to deposit functional polymer film and presented unique advantageous characteristics over wet-chemical approaches in that the bulk and surface properties can be controlled independently, which enabled the surface modification of materials with structural complexity or various delicate substrate susceptible to damage upon the exposure to a wet-chemicals [56-58]. The main advantage of iCVD originates from the mild deposition condition: the deposition process can be proceeded in solvent-free and near-room temperature condition. The initiator and monomers are vaporized and introduced simultaneously into the vapor phase reactor, then the injected monomers are adsorbed onto the surface of substrates, while the initiators decomposed thermally via hot filament to form radicals, which in turn trigger free-radical polymerization reaction at the substrate surface maintained near at room temperature (less than $50^{\circ} \mathrm{C}$ ), leading to the polymer film growth from the surface (Fig. 1). The chemical structures and application of iCVD polymers was listed in Table 1. The monomer and initiator in vapor phase can easily penetrated into the inner surface 


\section{iCVD process for 3-dimensional (3D) surface modification}

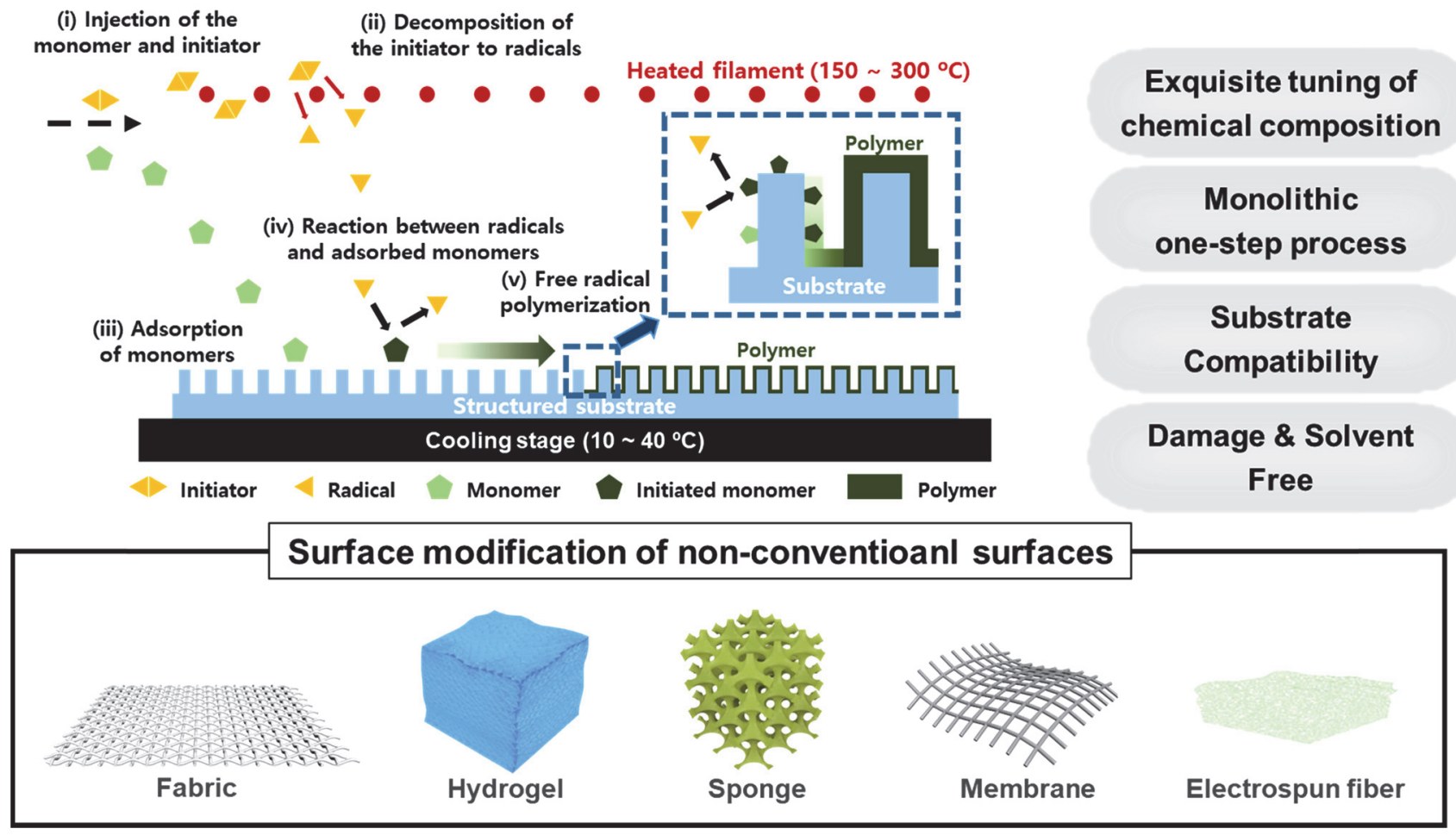

Fig. 1. A schematic illustration of iCVD technique for surface modification of 3-dimensional structures such as fabric, hydrogel, sponge, membrane, and electrospun fiber. (i) Vaporized monomers and initiators are injected into the iCVD reaction chamber. (ii) The injected initiators are thermally decomposed into the radicals by the heated filament (in the range of $150 \sim 300^{\circ} \mathrm{C}$ ). (iii) The injected monomers are adsorbed onto the surface of the structured substrate maintained near at room temperature (in the range of $10 \sim 40^{\circ} \mathrm{C}$ ). (iv-v) The radicals are transferred to the adsorbed monomers, which triggers free-radical polymerization reaction and polymer film growth from the surface.

of membrane pore and nano-/ micro-structures, allowing a conformal coating with sub-micron thickness and high conformal coverage without the loss of the structural integrity [59-61]. Moreover, the iCVD method enabled precise control of the chemical composition systemically. The evaporated monomer reactants can be mixed homogeneously in iCVD system regardless of their chemical properties, which allows the exquisite tuning of polymer compositions and facilitates the rational design of biomaterials that capable of satisfying the biochemical and functional requirements for the biomedical applications $[58,62,63]$.

The capability of iCVD techniques in engineering the surface of the non-conventional substrates allowed for the rational design of biomaterial platforms to control the adsorption/immobilization of bioactive molecules, thereby broadening the utility of biomaterials and providing a wide range of advanced approaches for biomedical applications. In addition, as biological and medical devices have been comprised of a range of miniature structures, conformal coating of micro- and nano-fabricated objects or devices are highly required. Significant developments in surface engineering using iCVD have been progressed in the last decade in the field of biomedical applications. In this review, recent developments toward surface functionalization and engineering of structured biomaterials are highlighted.

\section{Protein Immobilization on Non-conventional Substrates}

Non-conventional culture substrates with 3D micro/ nanostructures such as microbead [64,65], hydrogel [66-68], microfluidics channel [69-71], membrane [72], electrospun nanofiber [73], and paper [74-76] have been gained interest as a way to create novel or patient-specific biomedical devices in the field of as biotechnology and pharmaceuticals. For an advanced tissue engineering model, the trend in biomaterials has been moved from planar substrate to 3dimensional (3D) structure. In contrast to planar conventional culture surface, surface modification of the non-conventional culture surface possessing 3D micro/nanostructures have been suffered from low yield [77], heterogeneous treatment [78], and structure alteration [79] because of the solutionbased approaches. Therefore, to generate bioactive surface of non-conventional culture substrate, advanced surface 
Table 1. Chemical structures of iCVD polymers for biomedical applications

\begin{tabular}{|c|c|c|c|c|c|}
\hline $\begin{array}{l}\text { Polymer name } \\
\text { (Abbreviation) }\end{array}$ & Chemical structure & Application & $\begin{array}{l}\text { Polymer name } \\
\text { (Abbreviation) }\end{array}$ & Chemical structure & Application \\
\hline $\begin{array}{l}\text { Poly(glycidyl } \\
\text { methacrylate) } \\
\text { (pGMA) }\end{array}$ & & $\begin{array}{l}\text { Protein } \\
\text { immobiliza- } \\
\text { tion [77,78, } \\
100] \text {, } \\
\text { Cell } \\
\text { adhesion } \\
{[90]}\end{array}$ & $\begin{array}{l}\text { poly }(3,3,4,4,5,5,6,6,7, \\
7,8,8,9,9,10,10,10- \\
\text { heptadecafluorodecyl } \\
\text { methacrylate) } \\
\text { (pHFDMA) }\end{array}$ & & $\begin{array}{l}\text { Janus } \\
\text { property } \\
{[94,95]}\end{array}$ \\
\hline $\begin{array}{l}\text { Poly }(2,4,6,8- \\
\text { tetravinyl- } \\
2,4,6,8- \\
\text { tetramethyl } \\
\text { cyclotetrasiloxane) } \\
\text { (pV4D4) }\end{array}$ & & $\begin{array}{l}\text { Protein } \\
\text { immobiliza- } \\
\text { tion [76] }\end{array}$ & $\begin{array}{l}\text { Poly(4-vinylpyridine- } \\
\text { co-ethylene glycol } \\
\text { dimethacrylate) } \\
(\text { (4VP-co-EGDMA)) }\end{array}$ & & $\begin{array}{l}\text { Drug } \\
\text { delivery } \\
{[96]}\end{array}$ \\
\hline \multirow{2}{*}{$\begin{array}{l}\text { Poly }(1 \mathrm{H}, 1 \mathrm{H}, 2 \mathrm{H}, \\
2 \mathrm{H}- \\
\text { perfluorodecyl } \\
\text { acrylate) } \\
\text { (pPFDA) }\end{array}$} & & $\begin{array}{l}\text { Paper } \\
\text { scaffold } \\
{[90]}\end{array}$ & & & \\
\hline & & & $\begin{array}{l}\text { poly }(2- \\
\text { dimethylaminomethyl } \\
\text { styrene) (pDMAMS) }\end{array}$ & & $\begin{array}{l}\text { Nucleic } \\
\text { acid capture } \\
{[102,103]}\end{array}$ \\
\hline \multirow[t]{2}{*}{$\begin{array}{l}\text { Poly(styrene-co- } \\
\text { maleic } \\
\text { anhydride) } \\
\text { (PSMa) }\end{array}$} & & $\begin{array}{l}\text { Paper } \\
\text { scaffold } \\
{[91]}\end{array}$ & & & \\
\hline & & & $\begin{array}{l}\text { poly(trivinyltrimethyl } \\
\text { cyclotrisiloxane- } \\
\text { hexavinyldisiloxane) } \\
\text { (p(V3D3-co-HVDS)) }\end{array}$ & & $\begin{array}{l}\text { Neuropros- } \\
\text { thetic } \\
\text { device } \\
{[107]}\end{array}$ \\
\hline $\begin{array}{l}\text { Poly(ethylene } \\
\text { glycol } \\
\text { dimethacrylate) } \\
\text { (pEGDMA) }\end{array}$ & & $\begin{array}{l}\text { Surface } \\
\text { energy } \\
\text { control [92] }\end{array}$ & & & \\
\hline $\begin{array}{l}\text { Poly }(2- \\
\text { hydroyethyl } \\
\text { methacrylate) } \\
\text { (pHEMA) }\end{array}$ & $\mathrm{OH}$ & $\begin{array}{l}\text { Protein } \\
\text { fouling } \\
\text { [93], Drug } \\
\text { delivery } \\
\text { [97], Sensor } \\
\text { [106] }\end{array}$ & $\begin{array}{l}\text { poly(4-Vinylbenzyl } \\
\text { chloride-co-2- } \\
\text { (dimethylamino)ethyl } \\
\text { methacrylate) } \\
\text { (p(VBC-co- } \\
\text { DMAEMA) }\end{array}$ & & $\begin{array}{l}\text { Antibacterial } \\
\text { property } \\
{[108]}\end{array}$ \\
\hline
\end{tabular}


treatment technique such as iCVD [80-82], plasma treatment $[83,84]$, chemical etching $[85,86]$ have been investigated.

Plasma modification of surface have been known to enhance the biocompatibility by altering surface characteristic such as surface energy, charge, topography, and chemistry due to the energetic ion bombardment on the surface [87]. However, the mechanism of this energetic ions via surface treatment is still not clearly understood due to the chaotic nature of the plasma state, and the chemical identification of the plasma-treated surface is still vague [88]. Bilek et al. demonstrated the method to covalently immobilize proteins by facilitating buried radicals created by the energetic ions generated via plasma treatment on surface of polytetrafluor ethylene (PTFE), stainless steel, polystyrene (PS), and PDMS [83]. Free radicals reservoir beneath the surface was induced by the plasma-accelerated $\mathrm{N}$ ions, which allowed the covalent immobilization of proteins [89]. Bilek et al. utilized this method for covalent immobilization of proteins such as horseradish peroxidase or whole blood fluid on the surface [83]. Also, Martin et al. improved this plasma treatment method by varying the applied electric field to modulate the immobilization density and orientation of the bioactive peptides on the surface [90]. The orientationguided peptides were irreversibly immobilized on the radical functionalized surface. Reactive ion etching (RIE) was also utilized to incorporate textured structure on the polymer surface [91] and inorganic surfaces [92] or sterilization or cleaning of surface. Analogous to the plasma treatment, the chemical composition of the chemically etched surface is unclear, and the reproducibility of such surface treatment method should be assessed carefully. Rucker et al. developed functional antibody immobilization platform by RIE [85]. Chemically reactive species and reactive ion species can be generated by RIE on the surface of poly(methyl methacrylate) (PMMA), Zeonex ${ }^{\mathrm{TM}}$ and polycarbonate (PC), which could enhance the efficiency of surface protein immobilization. They also fabricated antibody array on the RIE-treated polymer surface with metal stencil mask to demonstrate their potential application to fluorescencebased immunoassay and protein patterning. Using this method, the blocking step to prevent nonspecific binding could be eliminated in immuno-assay.

iCVD does not damage most of substrate materials especially thermally or chemically vulnerable ones due to their gentle process condition, which make this method attractive to functionalize the surface of non-conventional culture substrate $[56,93]$. The functional moieties in the iCVD polymer films can also be utilized to immobilize bioactive molecules on iCVD polymer-deposited the surface. Jeong et al. introduced iCVD process for site-specific immobilization of proteins on polyethylene (PE) film and chromatography paper (Fig. 2A) [80]. They deposited poly (2,4,6,8-tetravinyl-2,4,6,8-tetramethyl cyclotetrasiloxane) (pV4D4) onto the substrate to enrich vinyl groups on its surface, which facilitate a covalent immobilization of cysteine-linked proteins via the ultraviolet (UV)-assisted thiol-ene click reaction. Kang et al. applied a conformal coating of poly(glycidylmethacrylate) (pGMA) to polycaprolactone (PCL) nanofiber using iCVD. The epoxy group in the conformally coated pGMA film could react with amine group of fibronectin (FN) to form a covalent immobilization of FN proteins on the PCL nanofiber. Surface modification with FN enhanced the degree of cell elongation, adhesion efficacy, and angiogenesis-related gene expression. 4 weeks after the transplantation of umbilicalcord-blood derived mesenchymal stem cells (UCB-MSCs)adhered nanofibers into the myocardial infarction (MI) model, the left ventricle ejection fraction and fraction shortening were increased and the myocardial infarction size and fibrosis were decreased remarkably compared to the non-treated control and acellular fibronectin-immobilized PCL nanofiber. Moreover, fibronectin-immobilized PCL containing UCB-MSCs alleviated myocardial infarction (MI) and fibrosis when they were implanted to rat MI model (Fig. 2B).

Youn et al. covalently immobilized bone morphogenetic protein-2 (rhBMP2) on titanium implant surface functionalized with pGMA in order to promote the osteogenesis of human adipose-derived stem cells (hADSCs) (Fig. 2C) [82]. The rhBMP2 was immobilized on titanium implant in a uniform manner with high coating efficiency, which significantly enhanced osteogenic differentiation and increased calcium deposition of hADSCs. These studies indicated the iCVD functional polymer film-mediated protein immobilization on non-conventional substrate makes the substrate more compatible with the surrounding tissue, resulting in the enhanced therapeutic efficacies.

\section{Surface Engineering of 3D Scaffolds}

\subsection{Tissue engineering}

Functional scaffold system is a demanding concept for advanced therapies in the regeneration and reconstruction of damaged organs and/or tissues. However, the limited availability in the surface functionalization method of 3D scaffold, especially nano-/micro- structures restricts their use in a wide range of biomedical applications. iCVD technique can generate various chemical and physical cues on the surface of the 3D scaffold surfaces.

Park et al. developed a paper-based bioactive scaffold for the stem cell-mediated bone tissue engineering through 
A
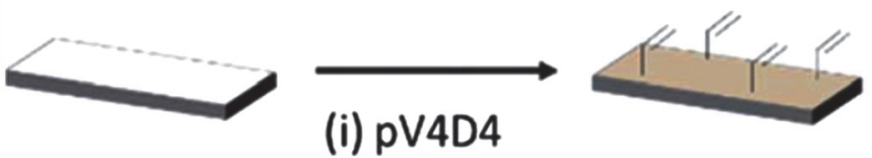

(i) $\mathrm{pV} 4 \mathrm{D4}$ coating
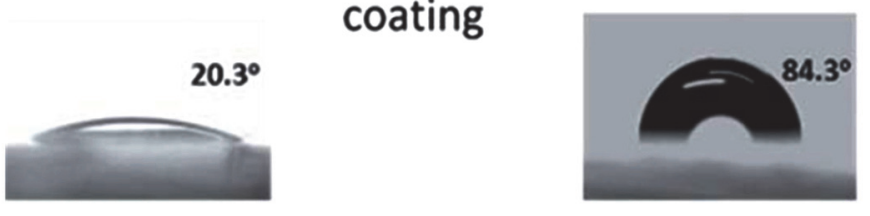

B
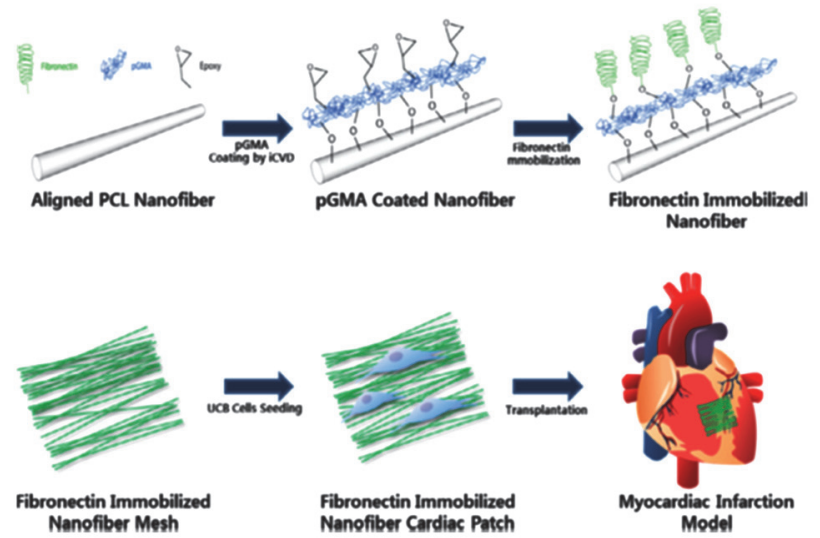

C
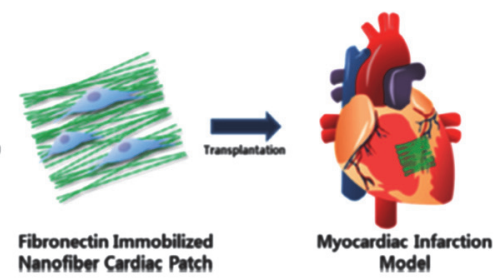

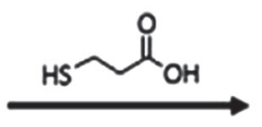

(ii) UV $(\lambda=365 \mathrm{~nm})$
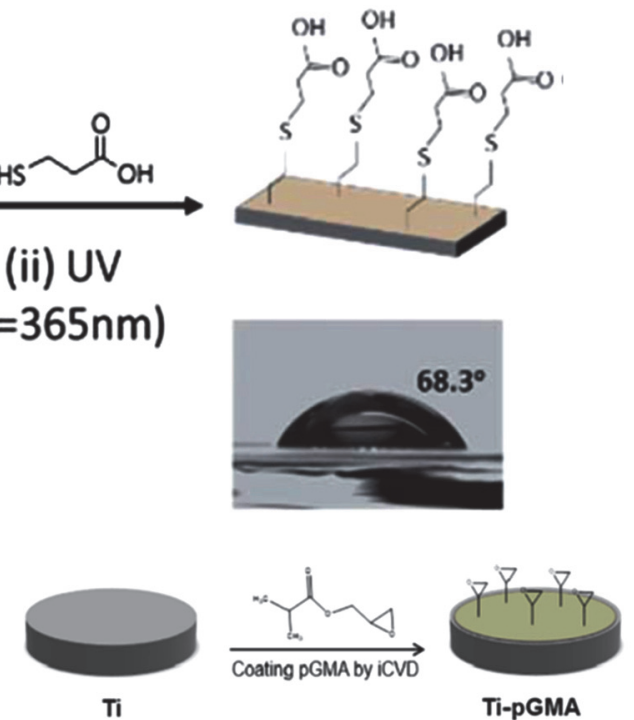

Ti
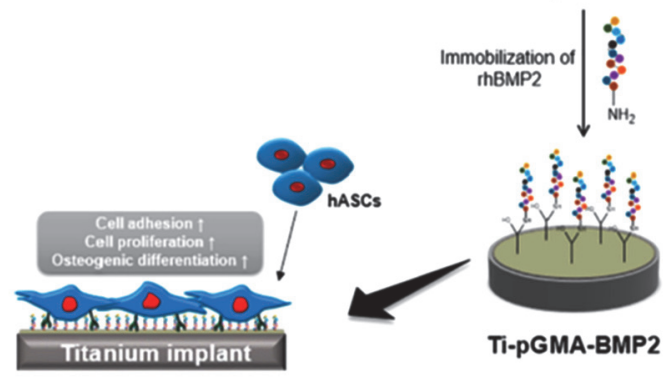

Fig. 2. iCVD process for surface bioactive modification for protein immobilization. (A) A vinyl functional group containing polymer, pV4D4 thin film synthesized in vapor-phase on the PE film facilitated site-specific immobilization of proteins by thiol-ene click reaction. Reproduced with copyright permission from [80]. (B), (C) A vinyl functional group containing polymer, pGMA was synthesized by iCVD process for surface modification of electrospun PCL and titanium implant respectively. Fibronectin and BMP2 protein were covalently immobilized on the surface. Reproduced with copyright permission from [81] and [82].

iCVD-mediated polymer coating [94]. For this purpose, a fluorinated polymer, poly $(1 \mathrm{H}, 1 \mathrm{H}, 2 \mathrm{H}, 2 \mathrm{H}-$ perfluorodecyl acrylate) (pPFDA) layer was deposited on paper scaffold surfaces to enhance the mechanical robustness by repelling water penetration into the paper scaffold. To improve the biocompatibility and to facilitate cell adhesion to the surface of the paper scaffolds, epoxy-containing pGMA layer was deposited successively onto the pPFDA-modified paper surface (Fig. 3A). The surface-engineered paper scaffolds exhibited remarkably increased mechanical stability, which is crucially important for long-term culture of hADSCs and in vivo applications. Biocompatible functional polymer coating also enhanced the osteogenic differentiation capacity of hADSCs, leading to substantial enhancement in in vivo bone regeneration when transplanted into a critical-sized calvarial bone defect.

Another interesting surface engineering of paper scaffold was investigated by Kim and coworkers to create a hydrogelladen multiform structure using an origami-based approach [57]. In this study, the paper surface was uniformly coated with a poly(styrene-co-maleic anhydride) via iCVD technique followed by physical adsorption of $\mathrm{Ca}^{2+}$ to induce the gelation of hydrogel and immobilization with poly-L-lysine to induce a strong electrostatic adhesion with the thin hydrogel layer. The hydrogel layer-containing chondrocytes was constructed on the surface-engineered paper scaffold by diffusion of $\mathrm{Ca}^{2+}$. The hydrogel-laden paper could be folded freely into arbitrary 3D structures of native tissue, leading to successful reconstruction of rabbit trachea when subjected to rabbit trachea.

Gelatin have been utilized in a variety of biomedical applications, but their weak mechanical property is often an obstacle to overcome. To rule out this concern, Mansurnezhad et al. proposed an efficient strategy to enhance the durability of gelatin nanofibers (GNFs). They coated the surface of electrospun GNF with poly(ethylene glycol dimethacrylate) (pEGDMA) via iCVD [95]. The wettability of the surfacemodified GNFs was changed from hydrophilic to hydrophobic, and the pEGDMA layer efficiently prevented the dissolution of GNF in aqueous media. The iCVD-GNFs 
A
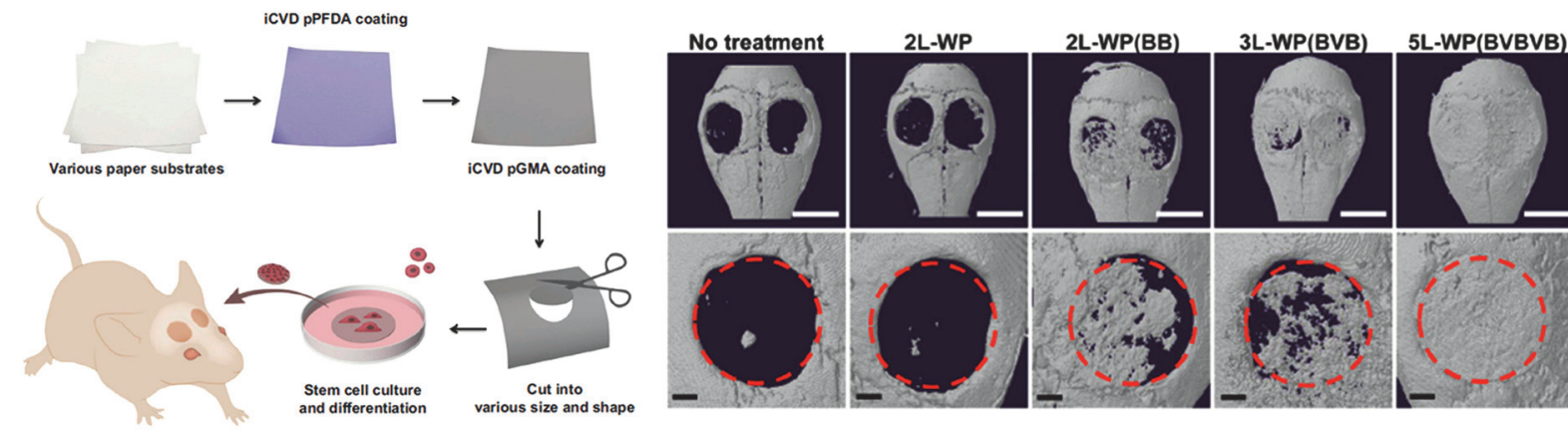

Implantation of stem cells

B

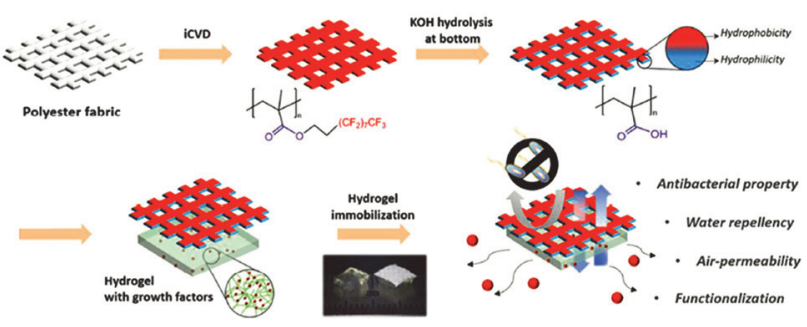

\begin{tabular}{|c|c|}
\hline Empty & Untreated \\
\hline G+T & $\begin{array}{c}\text { GelMA + } \\
\text { Tegaderm }^{\text {TM }}\end{array}$ \\
\hline$G+J$ & $\begin{array}{c}\text { GelMA + } \\
\text { Janus membrane }\end{array}$ \\
\hline$G+V+J$ & $\begin{array}{l}\text { GelMA + VEGF + } \\
\text { Janus membrane }\end{array}$ \\
\hline
\end{tabular}

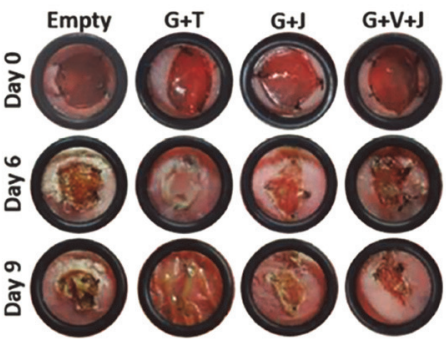

Fig. 3. Surface engineered 3D scaffolds and their in vivo applications. (A) A schematic illustration of fabrication of paper scaffolds via iCVD process (left) and an in vivo calvarial bone defect regeneration using the surface-modified paper scaffolds (right). pPFDA was synthesized on the surface of the paper scaffold to repel the water penetration into the paper scaffold, and epoxy-containing pGMA was synthesized on the pPFDA- modified paper to facilitate the cell adhesion via the direct interaction of pGMA with serum proteins. Reproduced with copyright permission from [94]. (B) A schematic procedure of the fabrication of gelatin methacrylate (GelMA) hydrogel-immobilized Janus membrane (left) and in vivo skin regeneration (right). pHFDMA was deposited on the polyester fabric to provide the Janus property. Reproduced with copyright permission from [98].

also showed high cytocompatibility for human fibroblast cells, implicating the usefulness of iCVD-GNF in biomedical applications such as wound healing.

A recent example of iCVD coating of catheters was proposed by Hanak and coworkers. The newly developed polymer-coated cerebrospinal fluid (CSF) shunt catheters was modified with poly(2-hydroyethyl methacrylate) (pHEMA) to decrease the attachment of cells such as brain's resident immune cells, reactive microglia and astrocytes [96]. The protein fouling is one of the critical factors required for medical-grade catheters otherwise life-threatening pediatric failures may happen by the reduction of CSF flow and consequently catheter obstruction. In an in vitro hydrocephalus catheter bioreactor, cells were clustered at the sidewalls of uncoated clinical-grade catheter and the CSF intake flow was reduced. However, on the pHEMA-coated catheters, cells formed a sparse monolayer along the hole side walls of the surface-modified catheters, revealing that pHEMA coating is an effective method to prevent the cell clustering on the catheter surface and thus can prevent the ventricular catheter obstruction resulted from direct attachment of innate immune cells of the central nervous system to the catheter surfaces.

\subsection{Drug delivery systems}

iCVD technique can also be utilized to control the drug delivery rate and direction to the target region by areaselective incorporation of surface functionality. For example, area-selective functionalization of membrane to provide Janus property exhibited a great potential for drug delivery applications. You et al. developed a Janus patch for mono-directional drug delivery [97]. A polyester fabric was coated with poly $(3,3,4,4,5,5,6,6,7,7,8,8,9,9,10,10,10$ heptadecafluorodecyl methacrylate) (pHFDMA) film by iCVD process (Fig. 3B). Then, one side of the substrate was subjected to base-catalyzed hydrolysis, rendering hydrophilic surface containing carboxylic acid residues. The hydrophobic surface prevented wetting by body fluids, while the hydrophilic surface allowed the coating of hydrogel incorporated with resveratrol and enhanced the adhesion of patch to mucosa. The Janus patch developed in this study enabled controlling the exact dose with intended directional drug release without allowing the water penetration. Furthermore, this approach is not restricted to polyester fabric but also can be extended to various kinds of porous materials such as Nylon mesh or paper.

In another study, An et al. utilized this Janus fabrication 
method to generate hydrogel functionalized Janus membrane [98]. The hydrophilic side of the Janus membrane was modified with gelatin methacrylate hydrogel to retain moisture and to release growth factor for the treatment of wound healing. Since the hydrophobic side can efficiently prevent the water penetration, directional delivery from hydrogel to skin can be accomplished. This Janus drug delivery system significantly improved the wound healing efficacy when implanted into mice with full-thickness dorsal skin defect models, implying a promising platform for the transmucosal delivery of various drugs.

iCVD technique can also be utilized for facile incorporation of stimuli-responsive properties into substrates. Sezin et al. proposed controlled $\mathrm{pH}$-responsive drug release system based on poly(4-vinylpyridine-co-ethylene glycol dimethacrylate) ( $\mathrm{p}(4 \mathrm{VP}-\mathrm{co}-\mathrm{EGDMA})$ )- coated electrospun nanofibers via iCVD process [99]. A chemotherapeutic drug, 4,5,6,7tetrachloro-2',4',5',7'-tetraiodofluoresceindisodium, also known as Rose Bengal was loaded in the electrospun nanofibers followed by a uniform coating of $\mathrm{p}$ (4VP-co-EGDMA) via iCVD process. The release kinetics of the drug from the nanofiber showed a distinct $\mathrm{pH}$-dependent behavior. The therapeutic efficiency of the $\mathrm{pH}$-responsive nanofiber mat was confirmed by analyzing their anti-cancer effects on glioblastoma multiforme cancer cells (U87MG).

Interesting example of biocompatible drug delivery system has also been described with drug-eluting stents (DES). Bedair et al. reported DES as a drug delivery system for the treatment of coronary artery diseases. The cobaltchromium (Co-Cr) alloy surface were uniformly coated with a highly crosslinked hydrophilic pHEMA film via iCVD process [100]. The hydroxyl groups of the pHEMA allowed the ring-opening polymerization with $\varepsilon$-caprolactone from the Co-Cr alloy surface, followed by spray-coating of a sirolimus-containing poly(D,L-lactide). The drug-inpolymer matrix on the surface modified $\mathrm{Co}-\mathrm{Cr}$ surface maintained for 7 weeks, indicating that the pHEMA coating as an interface layer contribute to the improved stability of the drug-in-polymer coating by preventing the swelling and detachment of the polymer coating from the stent surface.

\section{Structured Surface for Biomedical Applications}

The unique structural characteristics of the substrate material such as nano-patterned surfaces [101,102], membranes, and mesh filters, capable of providing additional functions to control the cell behavior and cell fate has been widely used for the research on its applications in tissue engineering and medical devices. However, most of structured substrates are made of chemically inert materials, and some problems such as bio-incompatibility or unwanted side effects may arise for biomedical applications, depending on the substrate materials [56]. To address this issue, it is critical to develop a reliable method capable of conformal coating of such structured surfaces while maintaining the original physical characteristics. iCVD process can provide various types of polymer coating on the various structured substrates in a uniform and conformal way without damaging the original structure of the substrate. Such advantageous properties of the iCVD process were utilized as a surface modification tool for a variety of applications including functional cell culture substrates, biosensors, and biomedical devices.

\subsection{Functional cell culture substrates}

Recently, biophysical effects including substrate topography and elastic modulus to the cell functions had been investigated intensively. In order to provide combined cues of chemical and physical factors to the cells, it is necessary to maintain the physical features of the original structures while providing proper biochemical cues through chemical surface functionalization. iCVD can introduce various chemical functionalities to structured substrates by depositing functional polymer thin films conformally without compromising the bulk physical properties.

Kim et al. established a peptide-functionalized cell culture platform with nanopatterned topography to enhance the osteogenic differentiation of stem cells [103]. Groove- and dot- patterned polyurethane acrylate (PUA) substrates in nanometer scale were prepared and coated with pGMA film conformally by the iCVD process. The pGMA can immobilize BMP-2 covalently through the amine-epoxy reaction (Fig. 4A). Therefore the surface-modified cell culture platform can simultaneously provide nanopattern-based physical cues and biochemical cues from the immobilized peptides. These coordinated surface cues successfully induced the enhanced osteogenic differentiation of the human mesenchymal stem cells (hMSCs) with and even without other soluble osteogenic factors. This result evidently demonstrated that iCVD polymer coating plays an important role in cell-nanotopography interactions including contact guidance.

\subsection{Diagnostics and biosensors}

Pandemic/epidemic infection caused by the worldwide spread of pathogens such as Middle East Respiratory Syndrome (MERS) or Coronavirus disease 2019 (Covid19) have led to the tremendous demand for effective and accurate detection of pathogens with high selectivity and sensitivity [104]. Typical pathogen diagnosis is based on the molecular analysis consisting of nucleic acid (NA) extraction step, a PCR amplification step, and an amplicon 
A

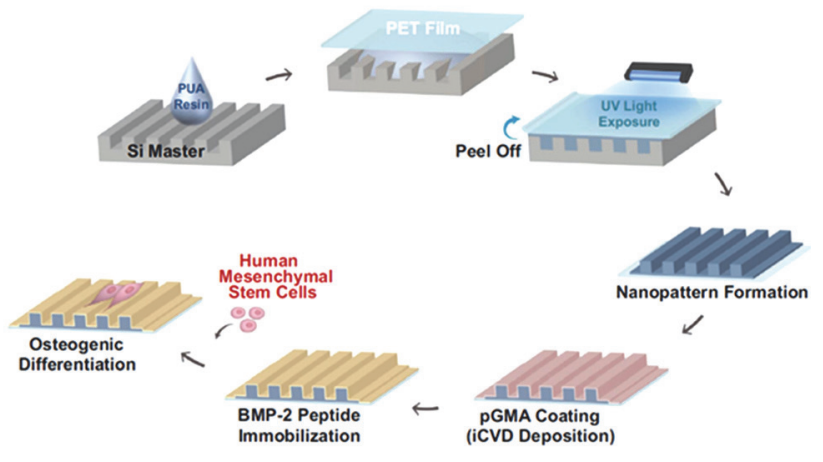

C

(i)

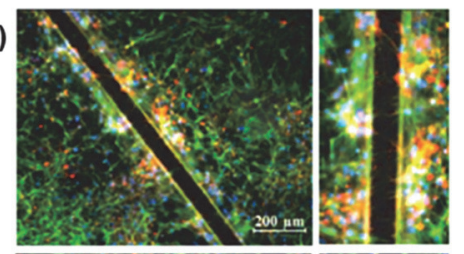

(ii)

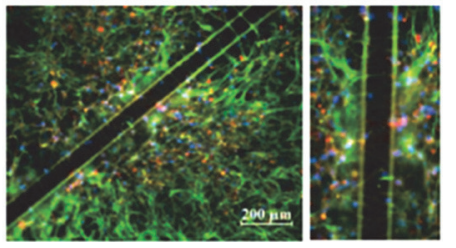

B
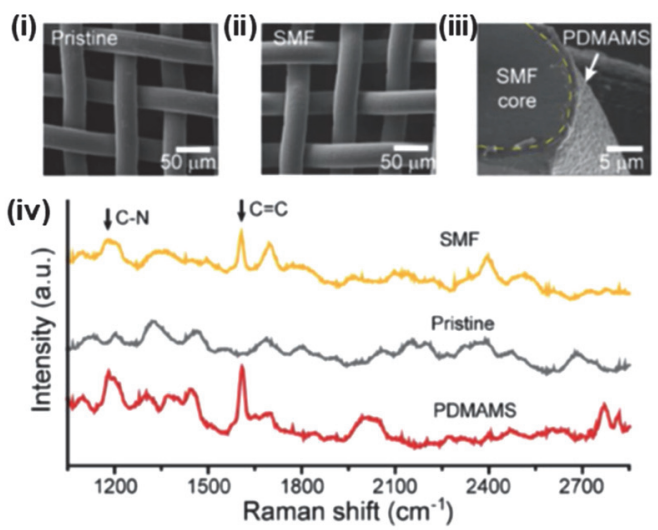

(ii)

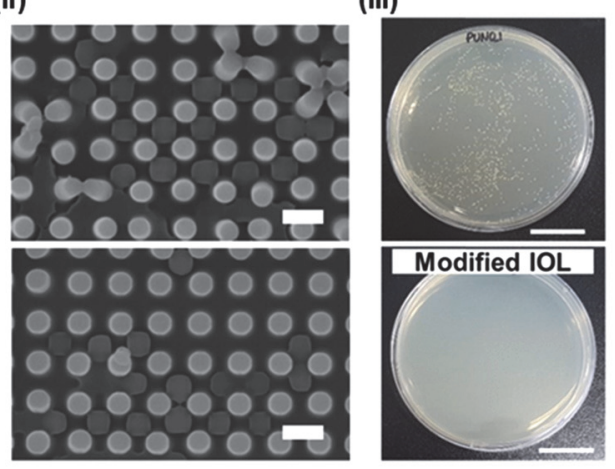

Fig. 4. (A) A schematic representation of the fabrication and surface functionalization of the BMP-2 peptide-functionalized PUA nanopatterned substrate for controlling the stem cell differentiation. pGMA film was deposited on nanopatterned substrate to immobilize BMP-2 covalently. Reproduced with copyright permission from [104]. (B) Scanning electron microscope (SEM) images of i) pristine mesh filter, ii) SMF, and iii) SMF with cross sectional view. iv) Raman spectrum of SMF (yellow), Pristine mesh filter (gray), and bulk pDMAMS (red). In SMF, pDMAMS was synthesized on a stainless steel mesh filter to introduce a strong electrostatic charge interaction with NA. Reproduced with copyright permission from [106]. (C) Representative fluorescence images showing the orientation of cells adhered on i) stainless steel microwire, and ii) p(V3D3-co-HVDS)-coated microwire stained for GFAP (green), Ox-42 (red), and cell nucleus (blue). p(V3D3-co-HVDS) was deposited on stainless steel microwire to provide the insulating property. Reproduced with copyright permission from [111]. (D) i) Photo and SEM image of the pVD-coated IOL. ii) SEM images of the NPA after incubation with S. aureus. iii) Representative images of bacterial colonies on control and pVD-modified IOL. The quaternary ammonium-containing polymer, pVD, was synthesized on IOL to provide the antibacterial property. Reproduced with copyright permission from [112].

analysis step with various detection tools. In particular, NA extraction process for obtaining high-purity deoxyribonucleic acid (DNA) is one of the most important steps for accurate analysis. However, most of the conventional NA extraction methods commonly demand the use of various toxic chemicals such as phenol, ethanol, and chloroform, and complicated steps including repeated centrifugation, vortexing, and heating, which critically limits their application to rapid but reliable on-site DNA detection systems essential for point-of-care technology (POCT). To overcome these limitations, solid-phase extraction (SPE) capable of NA capture through a surface-modification of substrates with wide applicability such as membrane and beads has been recently investigated. Most of surface-modification methods utilized in SPE are based on solution processes. However, the solution-based process is particularly problematic to be used for various structured substrates because it can cause many problems directly related to the detection sensitivity, such as non-uniformity, presence of residual reagent/ impurities, and long-term stability. To resolve this issue, iCVD process was utilized to modify the surface of the structured substrates with functional polymer coatings for efficient NA capture. You et al. investigated a cationic surface-modified mesh filter (SMF) capable of one step capture of NA directly from cell lysate (Fig. 4B) [105]. A cationic polymer, poly(2-dimethylaminomethyl styrene) (pDMAMS) was coated conformally on stainless steel mesh filter via iCVD. Strong electrostatic charge interaction between the pDMAMS-modified SMF and NA allowed the polymer surface to capture the negatively charged NAs. Through this platform, NAs were successfully extracted from Escherichia coli (E. coli) O157:H7 cell lysate and directly amplified by PCR. The target amplicon could be observed by the fluorescent signal on the DNA-captured 
polymer surface with the limit of detection (LOD) of $1.67 \times 10^{3}$.

In another case, Choi et al. applied this one step NA extraction method to develop a surface-modified NA extraction-integrated microchip [106]. The positively charged pDMAMS was directly coated on the inner wall of the polyethylene terephthalate (PET)-based microchip channel surface via iCVD, thereby enabled the direct capture of NA from $E$. coli $\mathrm{O} 157: \mathrm{H} 7$ cell lysate with high efficiency. This process enables a conformal surface functionalization of the biochip with complex structural features while minimizing the damage to the substrate. In particular, the pDMAMScoated NA extraction microchip exhibits high DNA capture efficiency greater than $90 \%$ directly from the cell lysates within $30 \mathrm{~min}$. Furthermore, this system also enables the extraction of the genomic DNAs from the real samples spiked with E. coli O157:H7. The developed NA extraction platform, which can directly capture the NA without additional steps, can be applied directly to various fields including molecular diagnosis, food safety inspection [107], and environmental pollutant detection [108].

Interesting approach for physiological monitoring had also been reported with the surface modification of unique particles. Ozaydin-Ince et al. proposed unique fluorescent sodium sensors which were called microworms because of its cylindrical shape [109]. pHEMA thin films were coated conformally onto AAO-membrane structure using the iCVD to enhance the biocompatibility for subcutaneous application and prolonged local retention time. Subsequently, the scaffolds were filled with optode and another layer of pHEMA was deposited to seal their ends. By conducting subcutaneous injection into mouse model, it was confirmed that the newly developed sensors were effective in vivo for the detection of physiological changes in real time by checking the $60 \%$ reduction of the diffusion away from the injection site, which in turn provides rapid response to the changes of sodium level. Furthermore, the response dynamics of those sensors could be tuned by simply adjusting the feed composition during iCVD which could result in the change of cross-linking density of the pHEMA films.

\subsection{Biomedical devices}

The surface modification of the biomedical devices is highly required particularly to overcome inflammation or allergic reactions and provide various additional functions such as biocompatibility, anti-bacterial, and insulating property. iCVD can be a promising tool to resolve the technical hurdles and improve the performance of biomedical devices.

Achyuta et al. prepared a novel organosilicon polymer thin film via iCVD for an insulation layer for neuroprosthetic devices [110]. In order to improve the long-term driving stability and performance of the neuroprosthetic devices, insulating materials capable of protecting the electronic circuitry should be included in the surface of neural implants. Organosilicon polymer film synthesized by iCVD are considered suitable candidates for insulating materials due to their highly cross-linked structure, excellent resistivity, and long-term chemical inertness (Fig. 4C). Immunocytochemistry analysis revealed that the organosilicon polymer thin film of poly(trivinyltrimethylcyclotrisiloxanehexavinyldisiloxane) (p(V3D3-co-HVDS)) showed the lowest fibronectin adsorption, thus confirming the lowest microglia cell number and astrocyte reactivity. The p(V3D3co-HVDS) was a biocompatible material that can fulfill the role of an insulating layer in neural prosthetic devices. Accordingly, the newly suggested surface functionalization method can serve as a new stabilization method for neural implants with biocompatible and insulating properties.

Choi et al. developed an ionic polymer-coated antibacterial nanopillar array (NPA) for preventing postsurgical intraocular lens (IOL) infection by pathogenic bacteria (Fig. 4D) [111]. The fabrication of an ionic polymer, poly(4-Vinylbenzyl chloride-co-2-(dimethylamino)ethyl methacrylate) (pVD) on the surface of NPA via iCVD allowed the capture and eradication of bacteria. The quaternary ammonium compounds of $\mathrm{pVD}$ could induce the destabilization and damage of the bacterial membrane combined with NPA dimensions because NPA with elastic properties can capture the bacteria through repetitive bending and restoration behaviors. The synergistic effect of physical and chemical modification resulted in an excellent antibacterial efficiency of over 99\% against Staphylococcus aureus (S. aureus) without cytotoxicity, illustrating a novel suggestion for preventing postoperative contamination after cataract and IOL replacement surgeries.

\section{Conclusion}

The exploration of the in vivo cellular microenvironment encourages researchers to attempt recapitulating such microenvironment with special materials and processes. Despite extensive ongoing research efforts to engineer the surface precisely, most of wet process still suffer from their hurdles need to be overcome. In this report, the recent progress in biofunctionalization by iCVD functional polymer thin films is reviewed. The established feasibility and versatility of the iCVD polymer films on substrate materials is particularly amenable to immobilization of bioactive molecules, site-specific conjugation, and facile control of physio-chemical property of implants and biomedical devices. Especially, the deposition of polymeric thin films in vapor phase monomers substantially facilitates adjusting the polymer compositions, which highlights the importance of iCVD technique in the precise topological 
and chemical control of medical implants with complex shapes. Most of all, in term of substrate-independent polymer coatings with nondestructive way, iCVD technique will make more significant contributions in the design and production of better biological and medical devices. Nevertheless, the development of iCVD functional polymer coatings for the application to various medical devices is in its budding stage. Therefore the improvement in the further in-depth biological assessment of polymer-coated surface is required in the aspect of direct surface contact of cell/tissue to understand the biomolecular mechanism underlying the series of cellular response on the functional polymer surface. In addition, a deeper investigation on the interactions of the iCVD polymer-functionalized surface and cell/tissue surface will provide great advantages for the rational design of the surface chemistry and develop elaborate medical devices responding to unmet medical needs. Moreover, mass production and quality control of iCVD polymer-coated medical device must also be developed for successful translation of laboratory investigation to clinical practice. Compared to conventional solution-based processes, the unique and advantageous iCVD process will resolve the technical hurdle to nonclinical and clinical pre-market success in both device manufacture and functional performance.

\section{Acknowledgements}

This work was supported by the National Research Foundation of Korea (NRF) grant funded by the Korea government (MSIP) (Grant 2021R1A2B5B03001416), Basic Science Research Program through the National Research Foundation of Korea (NRF) funded by the Ministry of Education (No. 2020R1I1A1A01066621) and the Technology Innovation Program (No. 20008777) funded by the Ministry of Trade, Industry \& Energy (MOTIE, Korea).

\section{Ethical Statements}

The authors declare no conflict of interest.

Neither ethical approval nor informed consent was required for this study.

\section{References}

1. Melchels, F. P. W., J. Feijen, and D. W. Grijpma (2010) A review on stereolithography and its applications in biomedical engineering. Biomaterials. 31: 6121-6130.

2. Mendes, P. M. (2008) Stimuli-responsive surfaces for bioapplications. Chem. Soc. Rev. 37: 2512-2529.

3. Patterson, J., M. M. Martino, and J. A. Hubbell (2010)
Biomimetic materials in tissue engineering. Mater. Today. 13: 14-22.

4. Lutolf, M. P. and J. A. Hubbell (2005) Synthetic biomaterials as instructive extracellular microenvironments for morphogenesis in tissue engineering. Nat. Biotechnol. 23: 47-55.

5. Rossini, P., P. Colpo, G. Ceccone, K. D. Jandt, and F. Rossi (2003) Surfaces engineering of polymeric films for biomedical applications. Mater. Sci. Eng. C. 23: 353-358.

6. Chu, P. K., J. Y. Chen, L. P. Wang, and N. Huang (2002) Plasma-surface modification of biomaterials. Mater. Sci. Eng. R. Rep. 36: 143-206.

7. Roach, P., D. Eglin, K. Rohde, and C. C. Perry (2007) Modern biomaterials: a review - bulk properties and implications of surface modifications. J. Mater. Sci. Mater. Med. 18: 1263-1277.

8. Asri, R. I. M., W. S. W. Harun, M. Samykano, N. A. C. Lah, S. A. C. Ghani, F. Tarlochan, and M. R. Raza (2017) Corrosion and surface modification on biocompatible metals: A review. Mater. Sci. Eng. C. Mater. Biol. Appl. 77: 1261-1274.

9. Campoccia, D., L. Montanaro, and C. R. Arciola (2013) A review of the biomaterials technologies for infection-resistant surfaces. Biomaterials. 34: 8533-8554.

10. Lim, J. Y. and H. J. Donahue (2007) Cell sensing and response to micro- and nanostructured surfaces produced by chemical and topographic patterning. Tissue Eng. 13: 1879-1891.

11. Bettinger, C. J., R. Langer, and J. T. Borenstein (2009) Engineering substrate topography at the micro- and nanoscale to control cell function. Angew. Chem. Int. Ed. Engl. 48: 5406-5415.

12. Nikkhah, M., F. Edalat, S. Manoucheri, and A. Khademhosseini (2012) Engineering microscale topographies to control the cellsubstrate interface. Biomaterials. 33: 5230-5246.

13. McMurray, R. J., N. Gadegaard, P. M. Tsimbouri, K. V. Burgess, L. E. McNamara, R. Tare, K. Murawski, E. Kingham, R. O. C. Oreffo, and M. J. Dalby (2011) Nanoscale surfaces for the longterm maintenance of mesenchymal stem cell phenotype and multipotency. Nat. Mater. 10: 637-644.

14. Kilian, K. A., B. Bugarija, B. T. Lahn, and M. Mrksich (2010) Geometric cues for directing the differentiation of mesenchymal stem cells. Proc. Natl. Acad. Sci. USA. 107: 4872-4877.

15. Bose, S., S. F. Robertson, and A. Bandyopadhyay (2018) Surface modification of biomaterials and biomedical devices using additive manufacturing. Acta Biomater. 66: 6-22.

16. Kim, Y. S., N. H. A. Raston, and M. B. Gu (2016) Aptamerbased nanobiosensors. Biosens. Bioelectron. 76: 2-19.

17. Sandhyarani, N. (2019) Surface modification methods for electrochemical biosensors. pp. 45-75. In: A. A. Ensafi (ed.). Electrochemical Biosensors. Elsevier, Amsterdam, Netherlands.

18. Mosbach, K. and O. Ramstrom (1996) The emerging technique of molecular imprinting and its future impact on biotechnology. Nat. Biotechnol. 14: 163-170.

19. Place, E. S., J. H. George, C. K. Williams, and M. M. Stevens (2009) Synthetic polymer scaffolds for tissue engineering. Chem. Soc. Rev. 38: 1139-1151.

20. Li, Y., J. Rodrigues, and H. Tomas (2012) Injectable and biodegradable hydrogels: gelation, biodegradation and biomedical applications. Chem. Soc. Rev. 41: 2193-2221.

21. Guo, B., L. Glavas, and A. C. Albertsson (2013) Biodegradable and electrically conducting polymers for biomedical applications. Prog. Polym. Sci. 38: 1263-1286.

22. Tian, H., Z. Tang, X. Zhuang, X. Chen, and X. Jing (2012) Biodegradable synthetic polymers: Preparation, functionalization and biomedical application. Prog. Polym. Sci. 37: 237-280.

23. O'Brien, F. J. (2011) Biomaterials \& scaffolds for tissue engineering. Mater. Today. 14: 88-95.

24. Song, H. G., R. T. Rumma, C. K. Ozaki, E. R. Edelman, and C. S. Chen (2018) Vascular tissue engineering: progress, challenges, and clinical promise. Cell Stem Cell. 22: 340-354. 
25. Sensharma, P., G. Madhumathi, R. D. Jayant, and A. K. Jaiswal (2017) Biomaterials and cells for neural tissue engineering: Current choices. Mater. Sci. Eng. C. Mater. Biol. Appl. 77: 1302-1315.

26. Bose, S., M. Roy, and A. Bandyopadhyay (2012) Recent advances in bone tissue engineering scaffolds. Trends Biotechnol. 30: 546-554.

27. Khang, D., J. Choi, Y. M. Im, Y. J. Kim, J. H. Jang, S. S. Kang, T. H. Nam, J. Song, and J. W. Park (2012) Role of subnano-, nano- and submicron-surface features on osteoblast differentiation of bone marrow mesenchymal stem cells. Biomaterials. 33: 5997-6007.

28. Variola, F., J. B. Brunski, G. Orsini, P. Tambasco de Oliveira, R. Wazen, and A. Nanci (2011) Nanoscale surface modifications of medically relevant metals: state-of-the art and perspectives. Nanoscale. 3: 335-353.

29. Dalby, M. J., N. Gadegaard, R. Tare, A. Andar, M. O. Riehle, P. Herzyk, C. D. W. Wilkinson, and R. O. Oreffo (2007) The control of human mesenchymal cell differentiation using nanoscale symmetry and disorder. Nat. Mater. 6: 997-1003.

30. Downing, T. L., J. Soto, C. Morez, T. Houssin, A. Fritz, F. Yuan, J. Chu, S. Patel, D. V. Schaffer, and S. Li (2013) Biophysical regulation of epigenetic state and cell reprogramming. Nat. Mater. 12: 1154-1162.

31. Cole, M. A., N. H. Voelcker, H. Thissen, and H. J. Griesser (2009) Stimuli-responsive interfaces and systems for the control of protein-surface and cell-surface interactions. Biomaterials. 30: $1827-1850$

32. Arima, Y. and H. Iwata (2007) Effect of wettability and surface functional groups on protein adsorption and cell adhesion using well-defined mixed self-assembled monolayers. Biomaterials. 28: 3074-3082.

33. Ayala, R., C. Zhang, D. Yang, Y. Hwang, A. Aung, S. S. Shroff, F. T. Arce, R. Lal, G. Arya, and S. Varghese (2011) Engineering the cell-material interface for controlling stem cell adhesion, migration, and differentiation. Biomaterials. 32: 3700-3711.

34. Keselowsky, B. G., D. M. Collard, and A. J. Garcia (2003) Surface chemistry modulates fibronectin conformation and directs integrin binding and specificity to control cell adhesion. J. Biomed. Mater. Res. A. 66: 247-259.

35. Hadden, W. J., J. L. Young, A. W. Holle, M. L. McFetridge, D. Y. Kim, P. Wijesinghe, H. Taylor-Weiner, J. H. Wen, A. R. Lee, K. Bieback, B. N. Vo, D. D. Sampson, B. F. Kennedy, J. P. Spatz, A. J. Engler, and Y. S. Choi (2017) Stem cell migration and mechanotransduction on linear stiffness gradient hydrogels. Proc. Natl. Acad. Sci. USA. 114: 5647-5652.

36. Yim, E. K. F., E. M. Darling, K. Kulangara, F. Guilak, and K. W. Leong (2010) Nanotopography-induced changes in focal adhesions, cytoskeletal organization, and mechanical properties of human mesenchymal stem cells. Biomaterials. 31: 1299-1306.

37. Cassidy, J. W., J. N. Roberts, C. A. Smith, M. Robertson, K. White, M. J. Biggs, R. O. C. Oreffo, and M. J. Dalby (2014) Osteogenic lineage restriction by osteoprogenitors cultured on nanometric grooved surfaces: the role of focal adhesion maturation. Acta Biomater. 10: 651-660.

38. Park, G. E., M. A. Pattison, K. Park, and T. J. Webster (2005) Accelerated chondrocyte functions on $\mathrm{NaOH}$-treated PLGA scaffolds. Biomaterials. 26: 3075-3082.

39. Gauvreau, V. and G. Laroche (2005) Micropattern printing of adhesion, spreading, and migration peptides on poly(tetrafluoroethylene) films to promote endothelialization. Bioconjug Chem. 16: 1088-1097.

40. Santiago, L. Y., R. W. Nowak, J. Peter Rubin, and K. G. Marra (2006) Peptide-surface modification of poly(caprolactone) with laminin-derived sequences for adipose-derived stem cell applications. Biomaterials. 27: 2962-2969.
41. Saleh, N. T., A. N. Sohi, E. Esmaeili, S. Karami, F. Soleimanifar, and N. Nasoohi (2019) Immobilized laminin-derived peptide can enhance expression of stemness markers in mesenchymal stem cells. Biotechnol. Bioprocess Eng. 24: 876-884.

42. Wang, T. H. and W. C. Lee (2003) Immobilization of proteins on magnetic nanoparticles. Biotechnol. Bioprocess Eng. 8: 263267.

43. Elmengaard, B., J. E. Bechtold, and K. Soballe (2005) In vivo study of the effect of RGD treatment on bone ongrowth on press-fit titanium alloy implants. Biomaterials. 26: 3521-3526.

44. Elmengaard, B., J. E. Bechtold, and K. Soballe (2005) In vivo effects of RGD-coated titanium implants inserted in two bonegap models. J. Biomed. Mater. Res. A. 75: 249-255.

45. Morra, M., C. Cassinelli, G. Cascardo, L. Mazzucco, P. Borzini, M. Fini, G. Giavaresi, and R. Giardino (2006) Collagen I-coated titanium surfaces: mesenchymal cell adhesion and in vivo evaluation in trabecular bone implants. J. Biomed. Mater. Res. A. 78: 449-458.

46. Reyes, C. D., T. A. Petrie, K. L. Burns, Z. Schwartz, and A. J. Garcia (2007) Biomolecular surface coating to enhance orthopaedic tissue healing and integration. Biomaterials. 28: 3228-3235.

47. Keselowsky, B. G., D. M. Collard, and A. J. Garcia (2005) Integrin binding specificity regulates biomaterial surface chemistry effects on cell differentiation. Proc. Natl. Acad. Sci. USA. 102: 5953-5957.

48. Wang, X., C. Yan, K. Ye, Y. He, Z. Li, and J. Ding (2013) Effect of RGD nanospacing on differentiation of stem cells. Biomaterials. 34: 2865-2874.

49. Petrie, T. A., J. R. Capadona, C. D. Reyes, and A. J. Garcia (2006) Integrin specificity and enhanced cellular activities associated with surfaces presenting a recombinant fibronectin fragment compared to RGD supports. Biomaterials. 27: 54595470

50. Shu, X. Z., K. Ghosh, Y. Liu, F. S. Palumbo, Y. Luo, R. A. Clark, and G. D. Prestwich (2004) Attachment and spreading of fibroblasts on an RGD peptide-modified injectable hyaluronan hydrogel. J. Biomed. Mater. Res. A. 68: 365-375.

51. Hersel, U., C. Dahmen, and H. Kessler (2003) RGD modified polymers: biomaterials for stimulated cell adhesion and beyond. Biomaterials. 24: 4385-4415.

52. Kantlehner, M., D. Finsinger, J. Meyer, P. Schaffner, A. Jonczyk, B. Diefenbach, B. Nies, and H. Kessler (1999) Selective RGD-mediated adhesion of osteoblasts at surfaces of implants. Angew. Chem. Int. Ed. Engl. 38: 560-562.

53. Li, B., J. Chen, and J. H. C. Wang (2006) RGD peptideconjugated poly(dimethylsiloxane) promotes adhesion, proliferation, and collagen secretion of human fibroblasts. J. Biomed. Mater. Res. A. 79: 989-998.

54. Sackmann, E. K., A. L. Fulton, and D. J. Beebe (2014) The present and future role of microfluidics in biomedical research. Nature. 507: 181-189.

55. Halldorsson, S., E. Lucumi, R. Gomez-Sjoberg, and R. M. T. Fleming (2015) Advantages and challenges of microfluidic cell culture in polydimethylsiloxane devices. Biosens. Bioelectron. 63: 218-231.

56. Yu, S. J., K. Pak, M. J. Kwak, M. Joo, B. J. Kim, M. S. Oh, J. Baek, H. Park, G. Choi, D. H. Kim, J. Choi, Y. Choi, J. Shin, H. Moon, E. Lee, and S. G. Im (2018) Initiated chemical vapor deposition: a versatile tool for various device applications. $A d v$. Eng. Mater. 20: 1700622.

57. Kim, S. H., H. R. Lee, S. J. Yu, M. E. Han, D. Y. Lee, S. Y. Kim, H. J. Ahn, M. J. Han, T. I. Lee, T. S. Kim, S. K. Kwon, S. G. Im, and N. S. Hwang (2015) Hydrogel-laden paper scaffold system for origami-based tissue engineering. Proc. Natl. Acad. Sci. USA. 112: 15426-15431.

58. You, J. B., Y. Yoo, M. S. Oh, and S. G. Im (2014) Simple and 
reliable method to incorporate the Janus property onto arbitrary porous substrates. ACS Appl. Mater. Interfaces. 6: 4005-4010.

59. Im, S. G., K. W. Bong, C. H. Lee, P. S. Doyle, and K. K. Gleason (2009) A conformal nano-adhesive via initiated chemical vapor deposition for microfluidic devices. Lab. Chip. 9: 411-416.

60. You, J. B., K. Kang, T. T. Tran, H. Park, W. R. Hwang, J. M. Kim, and S. G. Im (2015) PDMS-based turbulent microfluidic mixer. Lab. Chip. 15: 1727-1735.

61. Cha, S., K. Kang, J. B. You, S. G. Im, Y. Kim, and J. M. Kim (2014) Hoop stress-assisted three-dimensional particle focusing under viscoelastic flow. Rheol. Acta. 53: 927-933.

62. Kwak, M. J., M. S. Oh, Y. Yoo, J. B. You, J. Kim, S. J. Yu, and S. G. Im (2015) Series of liquid separation system made of homogeneous copolymer films with controlled surface wettability. Chem. Mater. 27: 3441-3449.

63. Baek, J., Y. Cho, H. J. Park, G. Choi, J. S. Lee, M. Lee, S. J. Yu, S. W. Cho, E. Lee, and S. G. Im (2020) A surface-tailoring method for rapid non-thermosensitive cell-sheet engineering via functional polymer coatings. Adv. Mater. 32: 1907225.

64. Ayhan, H. and E. Piskin (2000) Collagen immobilization onto P(EGDMA/HEMA) microbeads for cell affinity systems. $J$. Bioact. Compat. Polym. 15: 27-42.

65. Lee, S. J., J. P. Park, T. J. Park, S. Y. Lee, S. Lee, and J. K. Park (2005) Selective immobilization of fusion proteins on poly(hydroxyalkanoate) microbeads. Anal. Chem. 77: 5755-5759.

66. Yildirim, E. D., R. Besunder, D. Pappas, F. Allen, S. Guceri, and W. Sun (2010) Accelerated differentiation of osteoblast cells on polycaprolactone scaffolds driven by a combined effect of protein coating and plasma modification. Biofabrication. 2: 014109.

67. Vepari, C. P. and D. L. Kaplan (2006) Covalently immobilized enzyme gradients within three-dimensional porous scaffolds. Biotechnol. Bioeng. 93: 1130-1137.

68. Horne, M. K., D. R. Nisbet, J. S. Forsythe, and C. L. Parish (2010) Three-dimensional nanofibrous scaffolds incorporating immobilized BDNF promote proliferation and differentiation of cortical neural stem cells. Stem Cells Dev. 19: 843-852.

69. Rusmini, F., Z. Zhong, and J. Feijen (2007) Protein immobilization strategies for protein biochips. Biomacromolecules. 8: 1775-1789.

70. Kim, D. and A. E. Herr (2013) Protein immobilization techniques for microfluidic assays. Biomicrofluidics. 7: 41501.

71. Kim, H. J., J. N. Jin, E. Kan, K. J. Kim, and S. H. Lee (2017) Bacterial cellulose-chitosan composite hydrogel beads for enzyme immobilization. Biotechnol. Bioprocess Eng. 22: 89-94.

72. Raja, D. S., W. L. Liu, H. Y. Huang, and C. H. Lin (2015) Immobilization of protein on nanoporous metal-organic framework materials. Comments Inorg. Chem. 35: 331-349.

73. Mahmoudifard, M., S. Soudi, M. Soleimani, S. Hosseinzadeh, E. Esmaeili, and M. Vossoughi (2016) Efficient protein immobilization on polyethersolfone electrospun nanofibrous membrane via covalent binding for biosensing applications. Mater. Sci. Eng. C. Mater. Biol. Appl. 58: 586-594.

74. Zhao, M., H. Li, W. Liu, Y. Guo, and W. Chu (2016) Plasma treatment of paper for protein immobilization on paper-based chemiluminescence immunodevice. Biosens. Bioelectron. 79: 581-588.

75. Kong, F. and Y. F. Hu (2012) Biomolecule immobilization techniques for bioactive paper fabrication. Anal. Bioanal. Chem. 403: 7-13.

76. Hong, W., S. G. Jeong, G. Shim, D. Y. Kim, S. P. Pack, and C. S. Lee (2018) Improvement in the reproducibility of a paper-based analytical device (PAD) using stable covalent binding between proteins and cellulose paper. Biotechnol. Bioprocess Eng. 23: 686-692.

77. Borkenhagen, M., J. F. Clemence, H. Sigrist, and P. Aebischer (1998) Three-dimensional extracellular matrix engineering in the nervous system. J. Biomed. Mater. Res. 40: 392-400.

78. Waseem, S. F., S. D. Gardner, G. He, W. Jiang, and U. Pittman Jr (1998) Adhesion and surface analysis of carbon fibres electrochemically oxidized in aqueous potassium nitrate. $J$. Mater. Sci. 33: 3151-3162.

79. Yuguo, W., W. Yulin, W. Yizao, and D. Xianghong (2001) Effects of fiber surface treatment on mechanical properties of 3D braided carbon fiber/epoxy composite materials. Ordnance Mater. Sci. Eng. 2001: 41-44.

80. Jeong, G. M., H. Seong, Y. S. Kim, S. G. Im, and K. J. Jeong (2014) Site-specific immobilization of proteins on non-conventional substrates via solvent-free initiated chemical vapour deposition (iCVD) process. Polym. Chem. 5: 4459-4465.

81. Kang, B. J., H. Kim, S. K. Lee, J. Kim, Y. Shen, S. Jung, K. S. Kang, S. G. Im, S. Y. Lee, M. Choi, N. S. Hwang, and J. Y. Cho (2014) Umbilical-cord-blood-derived mesenchymal stem cells seeded onto fibronectin-immobilized polycaprolactone nanofiber improve cardiac function. Acta Biomater. 10: 3007-3017.

82. Youn, Y. H., S. J. Lee, G. R. Choi, H. R. Lee, D. Lee, D. N. Heo, B. S. Kim, J. B. Bang, Y. S. Hwang, V. M. Correlo, R. L. Reis, S. G. Im, and I. K. Kwon (2019) Simple and facile preparation of recombinant human bone morphogenetic protein-2 immobilized titanium implant via initiated chemical vapor deposition technique to promote osteogenesis for bone tissue engineering application. Mater. Sci. Eng. C Mater. Biol. Appl. 100: 949-958.

83. Bilek, M. M., D. V. Bax, A. Kondyurin, Y. Yin, N. J. Nosworthy, K. Fisher, A. Waterhouse, A. S. Weiss, C. G. dos Remedios, and D. R. McKenzie (2011) Free radical functionalization of surfaces to prevent adverse responses to biomedical devices. Proc. Natl. Acad. Sci. USA. 108: 14405-14410.

84. Montes-Morán, M. A., A. Martínez-Alonso, J. M. D. Tascón, M. C. Paiva, and C. A. Bernardo (2001) Effects of plasma oxidation on the surface and interfacial properties of carbon fibres/polycarbonate composites. Carbon. 39: 1057-1068.

85. Rucker, V. C., K. L. Havenstrite, B. A. Simmons, S. M. Sickafoose, A. E. Herr, and R. Shediac (2005) Functional antibody immobilization on 3-dimensional polymeric surfaces generated by reactive ion etching. Langmuir. 21: 7621-7625.

86. Lasseter, T. L., B. H. Clare, N. L. Abbott, and R. J. Hamers (2004) Covalently modified silicon and diamond surfaces: Resistance to nonspecific protein adsorption and optimization for biosensing. J. Am. Chem. Soc. 126: 10220-10221.

87. Junkar, I., U. Cvelbar, and M. Lehocky (2011) Plasma treatment of biomedical materials. Mater. Technol. 45: 221-226.

88. Simoncicova, J., S. Krystofova, V. Medvecka, K. Durisova, and B. Kalinakova (2019) Technical applications of plasma treatments: current state and perspectives. Appl. Microbiol. Biotechnol. 103: 5117-5129.

89. Bilek, M. M. and D. R. McKenzie (2010) Plasma modified surfaces for covalent immobilization of functional biomolecules in the absence of chemical linkers: towards better biosensors and a new generation of medical implants. Biophys. Rev. 2: 55-65.

90. Martin, L. J., B. Akhavan, and M. M. M. Bilek (2018) Electric fields control the orientation of peptides irreversibly immobilized on radical-functionalized surfaces. Nat. Commun. 9: 357.

91. Nabesawa, H., T. Hitobo, S. Wakabayashi, T. Asaji, T. Abe, and M. Seki (2008) Polymer surface morphology control by reactive ion etching for microfluidic devices. Sens. Actuators B Chem. 132: 637-643.

92. Ganjian, M., K. Modaresifar, H. Zhang, P. L. Hagedoorn, L. E. Fratila-Apachitei, and A. A. Zadpoor (2019) Reactive ion etching for fabrication of biofunctional titanium nanostructures. Sci. Rep. 9: 18815.

93. Choi, G., G. M. Jeong, M. S. Oh, M. Joo, S. G. Im, K. J. Jeong, and E. Lee (2018) Robust thin film surface with a selective antibacterial property enabled via a cross-linked ionic polymer 
coating for infection-resistant medical applications. ACS Biomater. Sci. Eng. 4: 2614-2622.

94. Park, H. J., S. J. Yu, K. Yang, Y. Jin, A. N. Cho, J. Kim, B. Lee, H. S. Yang, S. G. Im, and S. W. Cho (2014) Paper-based bioactive scaffolds for stem cell-mediated bone tissue engineering. Biomaterials. 35: 9811-9823.

95. Mansurnezhad, R., L. Ghasemi-Mobarakeh, A. M. Coclite, M. H. Beigi, H. Gharibi, O. Werzer, M. Khodadadi-Khorzoughi, and M. H. Nasr-Esfahani (2020) Fabrication, characterization and cytocompatibility assessment of gelatin nanofibers coated with a polymer thin film by initiated chemical vapor deposition. Mater. Sci. Eng. C Mater. Biol. Appl. 110: 110623.

96. Hanak, B. W., C. Y. Hsieh, W. Donaldson, S. R. Browd, K. K. Lau, and W. Shain (2018) Reduced cell attachment to poly(2hydroxyethyl methacrylate)-coated ventricular catheters in vitro. J. Biomed. Mater. Res. B. 106: 1268-1279.

97. You, J. B., A. Y. Choi, J. Baek, M. S. Oh, S. G. Im, K. E. Lee, and H. S. Gwak (2015) Application of monodirectional Janus patch to oromucosal delivery system. Adv. Healthcare Mater. 4: 2229-2236.

98. An, Y. H., S. J. Yu, I. S. Kim, S. H. Kim, J. M. Moon, S. L. Kim, Y. H. Choi, J. S. Choi, S. G. Im, K. E. Lee, and N. S. Hwang (2017) Hydrogel functionalized Janus membrane for skin regeneration. Adv. Healthcare Mater. 6: 1600795.

99. Sayin, S., A. Tufani, M. Emanet, G. G. Genchi, O. Sen, S. Shemshad, E. Ozdemir, G. Ciofani, and G. O. Ince (2019) Electrospun nanofibers with $\mathrm{pH}$-responsive coatings for control of release kinetics. Front. Bioeng. Biotechnol. 7: 309.

100. Bedair, T. M., S. J. Yu, S. G. Im, B. J. Park, Y. K. Joung, and D. K. Han (2015) Effects of interfacial layer wettability and thickness on the coating morphology and sirolimus release for drug-eluting stent. J. Colloid Interface Sci. 460: 189-199.

101. Baek, J., W. B. Jung, Y. Cho, E. Lee, G. T. Yun, S. Y. Cho, H. T. Jung, and S. G. Im (2019) Facile fabrication of high-definition hierarchical wrinkle structures for investigating the geometrysensitive fate commitment of human neural stem cells. ACS Appl. Mater. Interfaces. 11: 17247-17255.

102. Baek, J., S. Y. Cho, H. Kang, H. Ahn, W. B. Jung, Y. Cho, E. Lee, S. W. Cho, H. T. Jung, and S. G. Im (2018) Distinct mechanosensing of human neural stem cells on extremely limited anisotropic cellular contact. ACS Appl. Mater. Interfaces. 10: 33891-33900.

103. Kim, M. J., B. Lee, K. Yang, J. Park, S. Jeon, S. H. Um, D. I. Kim, S. G. Im, and S. W. Cho (2013) BMP-2 peptide-functionalized nanopatterned substrates for enhanced osteogenic differentiation of human mesenchymal stem cells. Biomaterials. 34: 7236-7246.

104. Jung, I. Y., J. B. You, B. R. Choi, J. S. Kim, H. K. Lee, B. Jang, H. S. Jeong, K. Lee, S. G. Im, and H. Lee (2016) A highly sensitive molecular detection platform for robust and facile diagnosis of Middle East Respiratory Syndrome (MERS) corona virus. Adv. Healthcare Mater. 5: 2168-2173.

105. You, J. B., Y. T. Kim, K. G. Lee, Y. Choi, S. Choi, C. H. Kim, K. H. Kim, S. J. Chang, T. J. Lee, S. J. Lee, and S. G. Im (2017) Surface-modified mesh filter for direct nucleic acid extraction and its application to gene expression analysis. Adv. Healthcare Mater. 6: 1700642.

106. Choi, Y., Y. T. Kim, S. J. Lee, E. Lee, K. G. Lee, and S. G. Im (2020) Direct solvent-free modification of the inner wall of the microchip for rapid DNA extraction with enhanced capturing efficiency. Macromol. Res. 28: 249-256.

107. Choi, Y., Y. T. Kim, J. B. You, S. H. Jo, S. J. Lee, S. G. Im, and K. G. Lee (2019) An efficient isolation of foodborne pathogen using surface-modified porous sponge. Food Chem. 270: 445451.

108. Shin, J., H. Kim, H. Moon, M. J. Kwak, S. Oh, Y. Yoo, E. Lee, Y. K. Chang, and S. G. Im (2018) A hydrogel-coated membrane for highly efficient separation of microalgal bio-lipid. Korean $J$. Chem. Eng. 35: 1319-1327.

109. Ozaydin-Ince, G., J. M. Dubach, K. K. Gleason, and H. A. Clark (2011) Microworm optode sensors limit particle diffusion to enable in vivo measurements. Proc. Natl. Acad. Sci. USA. 108: 2656-2661.

110. Achyuta, A. K. H., V. S. Polikov, A. J. White, H. G. P. Lewis, and S. K. Murthy (2010) Biocompatibility assessment of insulating silicone polymer coatings using an in vitro glial scar assay. Macromol. Biosci. 10: 872-880.

111. Choi, G., Y. Song, H. Lim, S. H. Lee, H. K. Lee, E. Lee, B. G. Choi, J. J. Lee, S. G. Im, and K. G. Lee (2020) Antibacterial nanopillar array for an implantable intraocular lens. Adv. Healthcare Mater. 9: 2000447.

Publisher's Note Springer Nature remains neutral with regard to jurisdictional claims in published maps and institutional affiliations. 